\title{
An Empirical Study of Technological Innovations in the Field of Accounting - Boon or Bane
}

\author{
Dr. Ahmad Khalid Khan ${ }^{1}$, Dr. Omar Abdullah Al Aboud ${ }^{1}$, Dr. Syed Mohammad Faisal ${ }^{1}$ \\ ${ }^{1}$ Department of Accounting, Faculty of Administrative Sciences, Jazan University, Kingdom of Saudi Arabia \\ Correspondence: Ahmad Khalid Khan, Department of Accounting, Faculty of Administrative Sciences, Jazan \\ University, Kingdom of Saudi Arabia
}

Received: February 5, 2018

Accepted: February 20, 2018

Online Published: February 26, 2018

doi:10.11114/bms.v4i1.3057

URL: https://doi.org/10.11114/bms.v4i1.3057

\begin{abstract}
In this paper researchers make an attempt by doing intense work that how technological innovations make jobs of accountant so easy from their routine jobs from posting to generating accounting statements etc. with the help of available software and technology in accounting field.

Technological innovations have changed an obstructed job of accountant into easier one and that too rapid and accurate, with these developments researchers have found and witnessed that it has affected erstwhile as it has restricted entry for so many into an accounting field as jobs of accountants have shrunk and in few hands who are technology accelerators and technology driven.
\end{abstract}

Researchers have shown how technology has affected the outcome and impact on business in terms of accuracy, pace and swiftness.

Researchers have made an attempt to explore various cause and effect relationship between available software in accounting, technology and accountants.

In their intense and in depth research we have designed questionnaire comprised of many questions in which respondents are selected from top management, employees and included job seekers too in order to receive their unbiased responses during primary data collection.

Wherever found necessary researchers have taken secondary data also to make study more accurate, interesting and feasible.

Keywords: technology, innovation, software, accounting, artificial intelligent robots

\section{Prologue}

Accounting is the language of business even wannabe accountant knows this. Accounting is the art of recording, classifying and summarizing in a significant manner and in terms of currency, dealings and procedures which are, in part at least, of monetary nature, and infer the outcome there of, Accounting can also be acknowledged as an information system that gauges, develops and converses fiscal inside story about an economic entity. Progressions in information machinery have considerably enhanced accounting systems and make over profitable life.

Accounting is the conveyor belt or escalator that carries an organization ahead. The accounting's endeavor is to reflect an organization's condition, by providing Balance Sheet and Profit \& Loss Account and many other relevant data for decision makers. Since inception of accounting language it has gone through many changes. All the revolution of technology has always played a positive role in making the Accounting language easier and accountant's job effortless. The accounting activity commenced to acquire on a complete innovative appearance towards the finish of the twentieth century. Technology has altered the Accounting industry entirely. The need for adding machines, calculators, ledgers and pencils was eliminated. Technological development in accounting made the work of accountant more reliable or with no margin of error and effortless or less tedious. The proficiency development for accountants which integrated the basic accounting, auditing and tax preparation is past. The use of the advance gadgets, accountant can take out arithmetical accounting or anticipate projects with better competence.

Today's accountant is no longer laden with task-oriented studies. The accounting industry is swiftly changing 
moderately due to yield optimization existing in the course of fresh equipment. Technological Innovation of Accounting has changed the role of Accountant and become business counselor from book keeper. Accountants will must cuddle the hasty progressing (staying equipped with technological trends, adapting current accounting software and optimizing to meet the needs of the firm, and being open to acknowledge and gain knowledge of advance technologies) in accounting technology if they want to remain relevant in the accounting industry. In a virtual sagacity and the internet has tattered down virtual borders and office walls, the facility available only to multinational corporations, now the technology has provided to small firms also and giving access to pool the talents and customers worldwide.

\section{What Is Technological Innovation in Accounting?}

Accounting programs now aid to accountants in their routine work for example journalizing the transactions, posting into ledgers, paying bills, and reporting. There are accounting software in the market that are easy to use and affordable, making them very popular with small business as well.

\section{Literature Review}

Hsu (2010) recapitulate Technological Innovation as single innovative tools scheme, employment of the accessible expertise for an original conceive and development of the obtainable tools or yields. For this article, Technological Innovation happens when a thought, method, service or artifact is recognized in the organization, and efficiently it faces the competition.

The influence of Technological Innovation on execution (both effectiveness and development) is mainly oblique and is instead revitalized by Information Technology (Dibrell et al., 2008). All through the decade of the 90's, Information Technology demonstrated to be a predominantly influential Technological Innovation means as it facilitated the progress of innovative goods and assisted progress trade methods; however the knowledge of innovative ingenious practices is a constant practice inside a firm and will outcome in an enhancement of procedure, goods and technique. This heave the subsequent query: How to innovate with information technology and Accounting Information System in an activity? How to achieve viable recompense through Accounting Information Systems? Thus, those firms' desires to innovate should inculcate the competences of Information Technology (Gordon and Tarafdar, 2007). These same researcher caution that Information Technology and the Information System could choke originality and Technological Innovation by homogenized, computerize and institutionalizing the accessible procedures and occupation surges. In the same way, according to Fink (2011), it is essential not to open its resources to replication or replacement, in order for a venture to maintain its viable lead. Likewise, an organization's capability to innovate and achieve viable gain depends on many things i.e. market regulations, human resources, R\&D stock, commitment (of goods and inhabitants) in global dealing, and etc. (Apergis et al., 2008).

Technological Innovation influences organizations capability to try to win effectively in a progressively more global market (Madrid-Guijarro et al., 2009), as Technological Innovation is fundamental to firms transformation and makeover (Feller et al., 2011). In this sense, firms not only require paying consideration to competence and output, but also they necessitate encouraging Technological Innovation and their methods to expand it which hold up understanding production, giving out and assimilation (Albers and Brewer, 2003). These two researchers define Technological Innovation as the use of information that proposes a fresh item for consumption or service desirable by customers. Nevertheless, the idea of Technological Innovation is multifaceted; and from the scientific and managerial point of view, it requires investment, time and devotion (Toledo and Zilber, 2012). Sala-I-Martin et al. (2013), Technological Innovation be capable of coming in the course of the technological feature or non-technological understanding. Principally, the Technological Innovation method is associated with the investigation, experimentation, improvement and execution of latest goods, services, procedures, thoughts and innovative managerial attitude.

Technological Innovation is a erratic that requirements to be encouraged inside the establishment, despite of the profits already expanded in the course of such Technological Innovation, of the construction of infrastructure, of the decrease of the macroeconomic volatility, or of the upgrading of the human resources of the populace, particularly because all these causes appear to dash into thinning profits (Sala-I-Martin et al., 2013). In this situation, this has ongoing to be converted into hard to carry on due to the retardation of many global economies. Furthermore, there is also the paucity of awareness about the imagination potential to raise the firm's innovative potential; as a result, it is crucial for firms to integrate into their hierarchical ethnicity the plan that Technological Innovation is vital for the organization (Toledo and Zilber, 2012). Undoubtedly, Technological Innovation is a reason that any sort of activity requirements to believe if they are to stay alive in these varying epoch. The Small and Medium Enterprises are not an exemption. This is especially true when there are large amounts of information available generated by Accounting Information System which have not been used for the general products in the Small and Medium Enterprises. Usually more simply or explicitly, for the Small and Medium Enterprises are also compulsory to generate the data within them, not only to fight, but also to stay alive. The character that Information Technology and Accounting Information System play in serving 
firms be converted into inventive is not clear. Nevertheless, because of the significance of Technological Innovation, many scholars have scrutinized its pedigree with the expectation of shaping what an organization should perform to turn into more innovative. Without hesitation more outlay in explore and improvement is required in order to comprehend and judge fresh Technological Innovation styles.

\section{Advantages of Technological Innovations in Accounting}

Technological Innovation has changed the role of an accountant and fashioned the new role, i.e. business consultant. The industry budged into the eighteenth years of twenty first century, with the higher and deeper knowledge of an accountant because the skilled labors jobs have been shifted to automation and accounting based software, here are some points that Technology Technological Innovation is making over the industry of accounting:

1) Cloud Computing -makes available collective computer dispensation resources and data to computers and other devices, since cloud computing is an internet-based computing and this breaks the walls of office in virtual sense, accountant can complete their tasks from any location and can generate and provide any information and reports through this technology. In the spare time accountant can deal the client and can develop business strategies rather remain occupied with loads of financial transactions.

2) Enterprise Resource Planning (ERP) Systems - The term ERP initially oblique systems considered to plan the utilization of firm-wide wherewithal. A classic ERP system will use several apparatus of computer software and hardware to attain the incorporation. For example, a software offers both accounting and payroll roles might theoretically be measured an ERP software package. Examples of modules in an ERP which previously would have been unconnected applications include: Human Resources, Customer Relationship Management, Supply Chain, Manufacturing, Warehouse Management and Financials.

3) Forensic Accounting - An expert of accounting and finance; pooled with examining methods and rule prepared it a perfect combo for investigating criminal fiscal dealings. Forensic accountants assist with construed whether transactions are illegitimate in such fields as; embezzlement, financial statement fraud, bankruptcies, money laundering, securities fraud, contract disputes, and insurance claims. In the early 2000's a corporate fraud with such company as Enron extremely inclined community awareness. Fresh rules were developed. Corporate fraud was being sincerely examined. These outrages in fact untie new opening for accountants in such areas as forensic accounting.

4) Mobile Accounting - Accountants are increasingly dependent on their mobile devices to accesses data. Accountants and clients gap bridges by Mobile connectivity. While on-the-move mobile applications assist accounting organizations supervise their dealing. With smart-phones organizations can reconcile, create expense claims, send invoices and add receipts from.

5) Optical Character Recognition (OCR) Technology - This kind of proof digitization has assisted modernize the archiving process by making documents searchable, and transportable. Another additional windfall to this sort of technology is that now accounting organizations are authorized to be agiler with their accounting practice. Facilitates accountants to transfer PDF files, or images captured by a digital camera and scanned paper documents into searchable and editable data.

6) Social Media - Social media has turn out to be an indispensable means for organizations planning to connect with their present and possible customers while getting bigger their product reach. As a tool Social media will continue to progress and make available accountants with an important marketing and sales stage that can immediately unite organizations to present and probable consumers.

7) Technological Innovations in Tax Software - The tax software of today has helped improve accuracy while reducing margins of error - something businesses want to embrace in order to avoid tax penalties and prevent issues with stake holders.

\section{Disadvantages of Technological Innovations in Accounting}

If the data are not investigated for accurateness and fullness, the accounting information produced by software will lead to misconception because all accounting data entered manually. It is essential for organization to educate human resources particularly to access and utilize the accounting software, which engross massive price and time. If rules change for taxes, accounting software involved to compute taxes is required to be redrafting for that reason to stay away from blunder.

Several of the accounting software needs to be personalized to match firms' necessities. Electricity failure, viruses, computer hackers may have an effect on automated systems if proper deterrent and safety measures are not in place.

Eventually menial jobs of book keeping in accounting world substituted with high pace by artificially intelligent robots or by Technological Innovation. Though it is unlikely that jobs required human skill cannot be overpowered by artificially intelligent robots for example developing accountancy for any company. 
If accountant desire to stay germane in the accounting industry, they will require adopting the hasty progress in technology in accounting field, This consist of keep on upto date with technological development, acclimatize and optimizing accounting software to convene the requirements of their organization and being unwrap to accommodating and educating progressing technologies. Disadvantages of accounting software are worth considering if firm is looking to apply in business, for example:

1) Implementation - physical accounts are normally easier to set up and can be extra elastic than computerized accounting. After setting up accounting software organization requires preliminary assistance.

2) Price - the cost package is more than the paper-based accounting system although small in relation to your other costs.

3) Specialized needs - Accounting Software generally suits good number of business kinds. However, whiz or specialized business houses may necessitate refining the package or changing their methods to use accounting software fruitfully.

4) Support - you may have to procure annual package and assistance for firm's software.

\section{Research Gap}

There is no drought of study material on technological innovation, surfeit of researches has been done on the technological innovation but no research work has been undertaken on the mentioned topic "An Empirical Study of Technological Innovations in the Field of Accounting - Boon or Bane" the researchers did courage to take up this topic and carry it to logical end.

\section{Objectives}

- To explore various aspects of technological innovations in the field of Accounting on society

- To find out the outcome of technological innovations in the field of Accounting

- To know the impact of technological innovations in the field of Accounting in the job market

- To point out relationship of technological innovations in the field of Accounting amongst Employers, Employees and Job Seekers

- To study, if technological innovations in the field of Accounting affect the business office walls virtually

\section{Research Methodology}

Our research is based on primary under mentioned:

Primary data

Population and sample

This study population consists of all resident of different cities of Kingdom of Saudi Arabia. The questionnaire was distributed to the aforesaid people and simultaneously authors also had verbal talk, whom 600 members representing the entire research population, the number of received questionnaire which valid for analysis was 473 , so the response rate was more than $73 \%$ from population's study.

\section{Measures}

We developed this questionnaire from many validated scales. Some changes were made to fit for our context. It consisted of total 15 questions out of which 5 questions selected for Society (Owners and Higher Management), 5 for employees and 5 for Job Seekers respectively.

Table. 1 Personal Details

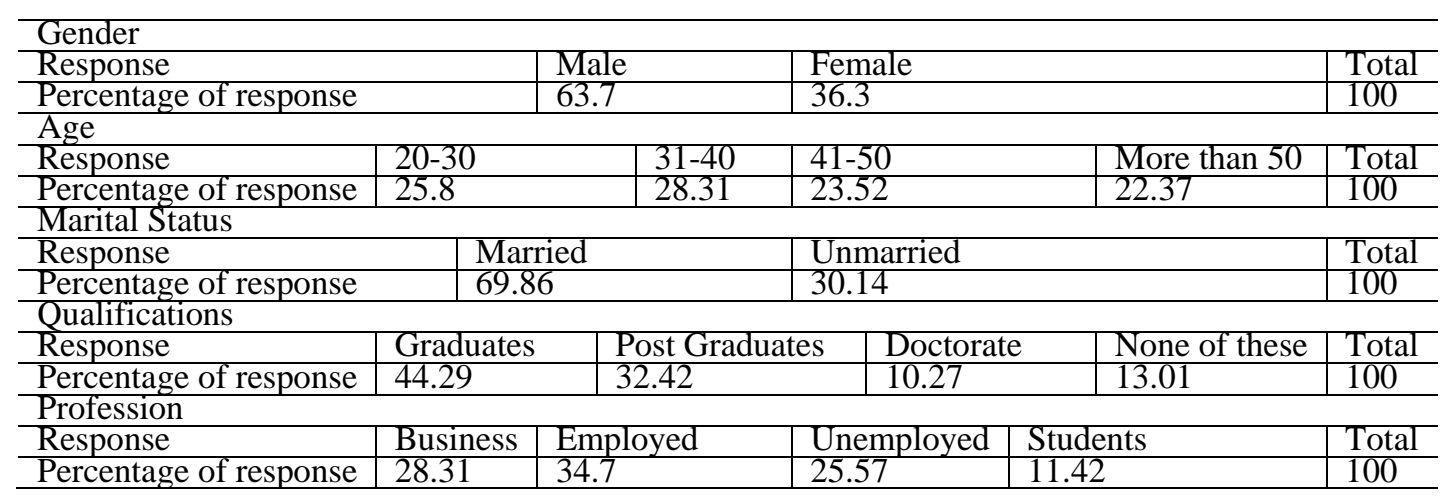


Data Analysis of Table 1.

Frequencies of sample's members are outlined in Table 1, which show $63 \%$ of sample are males, about $46 \%$ are middle aged $41-50$ years group and $54 \%$ are in the young age $20-40$ years group. Their marital status almost $70 \%$ members are married; their qualifications also varied from Graduates to Doctorates, 32\% of the members are Post Graduates $44 \%$ are Graduates and $10 \%$ are holding Doctorate Degree, sample members are mostly in employed i.e. $35 \%$ whereas $28 \%$ of the sample members are in business or top brass management officers very little amount of members are in students i.e. $11 \%$. One fourth of the sample members are job seekers.

Table 2. Society (Owners and Higher Management)

\begin{tabular}{c|c|c|c|c|c|c}
\hline \multicolumn{7}{c}{ Does Technological Innovation help in cost cutting? } \\
\hline Response & Strongly Disagree & Disagree & May be & Agree & Strongly Agree & Total \\
\hline Percentage of response & 4.11 & 8.22 & 4.79 & 7.76 & 75.11 & 100.00 \\
\hline Does society in high spirits with Technological Innovation? & Thet \\
\hline Response & Strongly Disagree & Disagree & May be & Agree & Strongly Agree & Total \\
\hline Percentage of response & 3.42 & 2.74 & 2.28 & 9.36 & 82.19 & 100.00 \\
\hline \multicolumn{7}{|c|}{ Does society changing from physical to digital? } \\
\hline Response & Strongly Disagree & Disagree & May be & Agree & Strongly Agree & Total \\
\hline Percentage of response & 3.88 & 2.97 & 5.71 & 8.45 & 79.00 & 100.00 \\
\hline Is Technological Innovation helpful for the owners and top management? \\
\hline Response & Strongly Disagree & Disagree & May be & Agree & Strongly Agree & Total \\
\hline Percentage of response & 2.05 & 3.88 & 3.65 & 16.44 & 73.97 & 100.00 \\
\hline \multicolumn{7}{|c|}{ Does Technological Innovation uplifting the standard of society? } \\
\hline Response & Strongly Disagree & Disagree & May be & Agree & Strongly Agree & Total \\
\hline Percentage of response & 1.60 & 1.14 & 4.79 & 13.47 & 79.00 & 100.00 \\
\hline
\end{tabular}

Data Analysis of Table 2.

Frequencies of sample's members are outlined in Table 2, which demonstrate in rejoinder of cost cutting $75 \%$ of sample population are strongly agreeing for cost cutting, very small i.e. $13 \%$ of the sample member disagree, they are of the view that the cost do not go down rather the nature of cost changes, the quantum of salary is reducing but the return on debt will shoot up. The society spirit is also high the sample members almost $83 \%$ reply in positive they argued that now society is also become impatient they need all the information by hitting just one button "Enter" and needs all information, $6 \%$ of the sample member argued that it is evolution of society. In the response to physical to digital sample member $79 \%$ replied in positive, society is changing from physical to digital in almost every field automation is taking place in every sphere of life, artificial robots are also being introduced with the name 'butler' just charge the butler for 5 hours it can work for 12 hours without sign of tiredness and with error free execution of work. Innovation also helped the higher management or owner, sample member responded in $74 \%$ in positive they argued that decision making becomes very trouble-free with diverse kind of reports as medical practitioners before diagnoses needs many investigative reports in the same way management get different report for decision making, almost $6 \%$ of sample members are of the view that it become time taking process first generate the report then go for decision making. Almost $82 \%$ of the sample members replied that absolutely technological Innovation has uplifted the standard of society, for example our forefathers' covers a distance in months that distance we are covering in minutes or hours.

Table 3. Employees

\begin{tabular}{c|c|c|c|c|c|c|c}
\hline \multicolumn{7}{c}{ Does Technological Innovation have torn down the office walls in virtual sense? } \\
\hline Response & Strongly Disagree & Disagree & May be & Agree & Strongly Agree & Total \\
\hline Percentage of response & 1.37 & 2.05 & 2.74 & 18.95 & 74.89 & 100.00 \\
\hline Is Technological Innovation converting organization into error free? \\
\hline Response & Strongly Disagree & Disagree & May be & Agree & Strongly Agree & Total \\
\hline Percentage of response & 2.74 & 0.68 & 3.42 & 11.64 & 81.51 & 100.00 \\
\hline \multicolumn{7}{|c|}{ Is Technological Innovation giving speed in execution of work? } \\
\hline Response & Strongly Disagree & Disagree & May be & Agree & Strongly Agree & Total \\
\hline Percentage of response & 3.88 & 5.25 & 2.05 & 4.79 & 84.02 & 100.00 \\
\hline Is Technological Innovation helping organization to take quick decision? \\
\hline Response & Strongly Disagree & Disagree & May be & Agree & Strongly Agree & Total \\
\hline $\begin{array}{c}|c| \\
\text { Percentage of response }\end{array}$ & 2.97 & 3.88 & 2.74 & 12.33 & 78.08 & 100.00 \\
\hline Does every accountant must exert effort to cope up with the pace of Technological Innovation,? \\
\hline Response & Strongly Disagree & Disagree & May be & Agree & Strongly Agree & Total \\
\hline Percentage of response & 0.46 & 3.65 & 2.28 & 35.16 & 58.45 & 100.00 \\
\hline
\end{tabular}


Data Analysis of Table 3.

Frequencies of sample's members are outlined in Table 3, which demonstrate in rejoinder of $75 \%$ of sample population are strongly agreeing torn down the office wall, employees are of the view that the they can be in touch with accounting development from anywhere due to cloud system and can be in touch with their present and prospective customers from anywhere for that they don't have to be in office chair. If we go through the table number II we see $78 \%$ to $84 \%$ accountants are very much satisfied with the technological innovation as it eased the work along with error free work with quick execution of work and fast decision can be made, very small chunk is unsatisfied that ranges 3 to $4 \%$ they argue technological innovation is taking place in machine or computer and they are not real intelligent they are dependent on many things like Power supply, annual maintenance, antivirus, hackers proofs, storage backup and controlled by human being, simultaneously they are also worried since they have to keep them update with technological change.

Table 4. Job Seekers

\begin{tabular}{|c|c|c|c|c|c|c|c|}
\hline \multicolumn{8}{|c|}{ Does Technological Innovation uplifting the standard of education } \\
\hline Response & Strongly Disagree & & \begin{tabular}{l|l} 
Disagree \\
\end{tabular} & May be & Agree & Strongly Agree & Total \\
\hline Percentage of response & 2.74 & & \begin{tabular}{l|l|}
6.62 \\
\end{tabular} & 3.88 & 4.34 & 82.42 & 100.00 \\
\hline \multicolumn{8}{|c|}{ Are jobs shrinking in the market due to Technological Innovation? } \\
\hline Response & \begin{tabular}{l|l} 
Strongly Dis \\
\end{tabular} & agree & Disagree & May be & Agree & Strongly Agree & Total \\
\hline Percentage of response & 1.14 & & 7.08 & 5.48 & 2.51 & 83. & 100.00 \\
\hline \multicolumn{8}{|c|}{ Is Technological Innovation a threat for the jobs seekers? } \\
\hline Response & Strongly Disagree & Disagree & & May be & Agree & gly Agree & Total \\
\hline Percentage of response & 3.20 & 4.11 & & 21.92 & 7.76 & 63.01 & 100.00 \\
\hline \multicolumn{8}{|c|}{ Is Technological Innovation changing the nature of jobs? } \\
\hline Response & Strongly Disagree & Disagree & & y be & Agree & ongly Agree & Total \\
\hline Percentage of response & 13.01 & 16.67 & & 9.82 & 25.80 & 34.70 & 100.00 \\
\hline \multicolumn{8}{|c|}{ Is Technological Innovation helpful for job seekers? } \\
\hline Response & Strongly Disagree & Disagree & & May be & Agree & Strongly Agree & Total \\
\hline Percentage of response & 55.25 & 28.31 & & 5.48 & 4.11 & 6.85 & 100.00 \\
\hline
\end{tabular}

Data Analysis of Table 4.

Frequencies of sample's members are outlined in Table 4, which demonstrate in riposte of $83 \%$ of sample population are strongly agreeing that the standard of the education has gone up due to easy availability of study material, it has also torn down the wall of schools and universities in virtual sense, from any place online they can attend the lectures and take their examinations. This is one of the hard fact for which $84 \%$ has agreed that jobs market has shrunk and automation is replacing human labor force. Job seekers are feeling suffocated in getting jobs $63 \%$ of the sample members agreed and argued that they have direct competition with machines which is very difficult to catch up. Sample members have given mixed response in the changing nature of jobs where more than $60 \%$ agreed the quantum of job is same only the nature is changing whereas $40 \%$ of the sample members replied that nature of job is not changing rather human labor is replaced by the artificial intelligent machines, since business houses are not creating "Ecosystem" and that will lead to dangerous to the society. In response to helpful in searching of jobs $17 \%$ of the sample members agreed that they have global excess where as $83 \%$ disagree with this logic they are of the view that human has to snatch the jobs from the jaws of machine which is next to impossible.

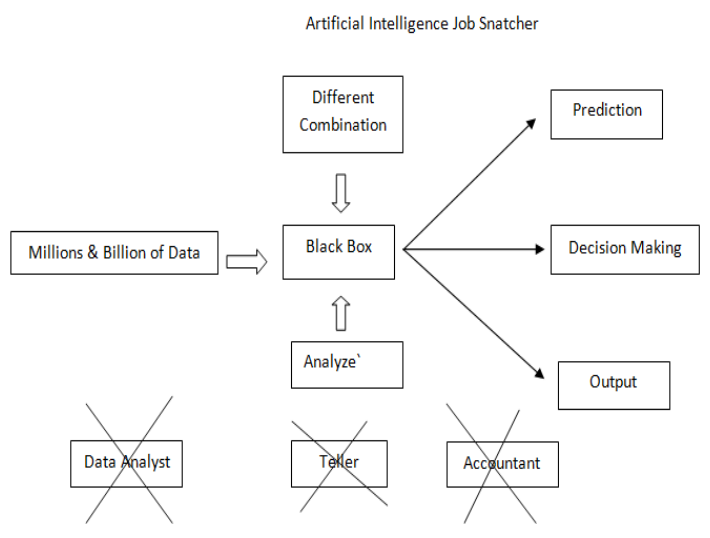

Figure 1. Artificial Intelligence Job Snatcher

Note: prepared by the researchers 
Technological Innovation is taking place with such a velocity that it will gulp the job of masses (like Data analyst, teller, accountant and etc), in the black box of artificial intelligent robot's filled with millions and billions of data in different combination and permutation and it will analyze any data that will help in prediction and decision making hence it will amplify the output of the organization many folds. Since human has exhausting tendency whereas machine don't get tired. The beauty of technological innovation, masses is losing their jobs still they are appreciating the technological innovation.

\section{Epilogue and Further Research}

Technological Innovation has changed the face of the world; it has made all the jobs easy and less tedious in every walk of life in general and in the field of accounting in particular. Innovation has not only changed the business world life, it has made easy life in every sphere whether it is economic life, political life, geographical life, religious rituals and etc. But everything is appreciable if it is used for the betterment of the society, now economy is concentrating, richer is becoming more rich and poorer are becoming more poor due to automation, masses are losing jobs, in such a situation classes will also not survive for longer. When masses will lose their purchasing power, who will be the customer of classes? The time is not far when the world will have to revisit on the decision of technological innovations, in researchers opinion it is maximum 10 years, if they will not create ecosystem.

Nokia happened to be one of the pioneers in mobile phone industry and giant company but it committed a mistake, it didn't create the ecosystem as well as not cared for carrying \& forwarding agents, whole sellers, retailers and clients, as a result in the course of time they have been struggling for their existence.

Furthermore, Technological development and innovations are not limited only for the world of accounting and snatching the jobs of accountant rather jobs are shrinking as whole in business world and since economy is concentrating in few hands due to automation and it is a matter of concern and it flashes light for new area of researches.

\section{References}

Albers, J. A., \& Brewer, S. (2003). Knowledge management and the Technological Innovation process: The Eco-Technological Innovation Model. Journal of Knowledge Management Practice, 4, 1-10.

Apergis, N., Economidou, C., \& Filippidis, I. (2008). Technological Innovation, technology transfer and labor productivity linkages: Evidence from panel of manufacturing industries. Review of World Economics, 144(3), 491-508. https://doi.org/10.1007/s10290-008-0157-9

Chen, Y. C., \& Wu, J. H. (2011). IT management capability and its impact on the performance of a CIO. Information \& Management, 48, 145-156. https://doi.org/10.1016/j.im.2011.04.001

Chin, W. W., Marcolin, B., \& Newsted, P. (2003). A Partial Least Squares latent variable modeling approach for measuring interaction effects: Results from a Monte Carlo simulation study and an electronic-mail emotion/adoption study. Information Systems Research, 14(2), 189-217. https://doi.org/10.1287/isre.14.2.189.16018

Chin, W. W. (1998b). The partial least squares approach to structural equation modelling. In: Marcoulides, GA. (Ed.), Modern methods for business research (295-336). Nahwah, NJ: Lawrence Erlbaum

Dibrell, C., Davis, P. S., \& Creig, J. (2008). Fueling Technological Innovation through information technology in SMEs. Journal of Small Business Management, 46(2), 203-218.

Dillon, T. W., \& Kruck, S. E. (2004). The emergence of accounting information systems programs. Management Accounting Quarterly, 5(3), 29-36.

Feller, J., Finnegan, P., \& Nilsson, O. (2011). Open Technological Innovation and public administration: transformational typologies and business model impacts. European Journal of Information Systems, 20, 358-374. https://doi.org/10.1057/ejis.2010.65

Feurer, R., K. Chaharbaghi, M., Weber, \& Wargin, J. (2000). Aligning strategies, processes, and IT: A case study. IEEE Engineering Management Review, 17(1), 23-34. https://doi.org/10.1201/1078/43190.17.1.20000101/31211.4

Fink, L. (2011). How do IT capabilities create strategic value? Toward greater integration of insights from reductionistic and holistic approaches. European Journal of Information Systems, 20, 16-33. https://doi.org/10.1057/ejis.2010.53

Fornell, C., \& Larcker, D. F. (1981). Evaluating Structural Equation Models with unobservable variables and measurement error. Journal of Marketing Research, 18(1), 39-50. https://doi.org/10.2307/3151312

Gordon, S. R., \& Tarafdar, M. (2007). How do a company's information technology competences influence its ability to 
innovate? Journal of Enterprise Information Management, 20(3), 271-290. https://doi.org/10.1108/17410390710740736

Han, C. C., Hsieh, F. L., \& Li, X. (2011). Information technology investment and manufacturing worker productivity. Journal of Computer Information Systems, 52(2), 51-60.

Henderson, J., \& Venkatraman, N. (1993). Strategic alignment: Leveraging information technology for transforming organizations. IBM Systems Journal, 32(1), 4-16. https://doi.org/10.1147/sj.382.0472

Hevner, A. R., March, S. T., \& Park, J. (2004). Design science in information systems research. MIS Quarterly, 28(1), 75-104. https://doi.org/10.2307/25148625

Hitt, L. M., \& Brynjolfsson, E. (1996). Productivity, business profitability, and consumer surplus: Three different measures of information technology value. MIS Quarterly, 20(2), 121-142. https://doi.org/10.2307/249475

Hsu, J. (2010). Effectiveness of technology transfer measures in improving SME productivity: An empirical study of Taiwan. The Journal of American Academy of Business, 15(2), 206-211.

Jarvenpaa, S. L., \& Ives, B. (1993). Organizing for global competition: The fit of information technology. Decision Science, 24(3), 547-580. https://doi.org/10.1111/j.1540-5915.1993.tb01293.x

Lin, C., Wu, J., \& Yen, D. C. (2012). Exploring barriers to knowledge flow at different knowledge management maturity stages. Information \& Management, 49, 10-23. https://doi.org/10.1016/j.im.2011.11.001

Madrid, G. A., Garcia, D., \& Vanauken, H. (2009). Barriers to Technological Innovation among Spanish manufacturing SMEs. Journal of Small Business Management, 47(4), 665-487.

Mahmood, M. A., Burn, J. M., Gemoets, L. A., \& Jacquez, C. (2000). Variables Affecting Information Technology End-User Satisfaction: A Meta-analysis of the Empirical Literature. International Journal of Human Computer Studies, 52(4), 751-771. https://doi.org/10.1006/ijhc.1999.0353

Omar, A. (2017). An Investigation of Indian Security Market, the Viewpoint Of FMCG Companies Who Voyage From Good To Great. International Journal of Economics, Commerce and Managemen, $t$ United Kingdom, 1033-1046.

Oppenheim, C., Stenson, J., \& Wilson, R. M. S. (2004). Studies on Information as an Asset III: Views of Information Professionals. Journal of Information Science, 30(2), 181-190. https://doi.org/10.1177/0165551504042809

Peak, D., Guynes, C. S., \& Kroon. (2005). Information technology alignment planning - A case study. Information \& Management, 42(3), 619-633. https://doi.org/10.1016/S0378-7206(04)00077-1

Petter, S., DeLone, W., \& McLean, E. (2008). Measuring information systems success: models, dimensions, measures, and interrelationships. European Journal of Information Systems, 17, 236-263. https://doi.org/10.1057/ejis.2008.15

Ringle, C. M., Wende, S., \& Will, A. (2005). SmartPLS 2.0 (beta). http://www.smartpls.de. Consulted: May $10,2013$.

Sala, X., Bilbao, B., Blanke, J., Crotti, R., Drezeniek, M., Geiger, T., \& Ko, C. (2013). The Global Competitiveness Index 2012-2013: Strengthening Recovery by Raising Productivity. In The Global Competitiveness Report 2012 2013. Ed. K. Schwab. World Economic Forum. Switzerland

Sala, X., Blake, J., Drezeniek, M., Geiger, T., Mia, I., \& Paua, F. (2008). The Global Competitiveness Index: Prioritizing the Economic Policy Agenda, In The Global Competitiveness Report 2008-2009. Ed. Porter, M., and L. Schwab. World Economic Forum. Switzerland

Syed, K., \& Aboud, A. (2017). Study of Managerial Decision Making Linked to Operating and Financial Leverage. https://doi.org/10.5430/afr.v7n1p139

Toledo, L. A., \& Zilber, M. A. (2012). An analysis of the fallacy of taking apart technology and Technological Innovation. Revista de Administração e Inovação, 9(1), 211-230.

Venkatranman, N. (1989). The concept of fit in strategy research: Toward verbal and statistical correspondence. Academy of Management Review, 14(2), 423-444.

\section{Copyrights}

Copyright for this article is retained by the author(s), with first publication rights granted to the journal.

This is an open-access article distributed under the terms and conditions of the Creative Commons Attribution license which permits unrestricted use, distribution, and reproduction in any medium, provided the original work is properly cited. 